\title{
THE ETIOLOGY OF INTERMITTENT OESOPHAGEAL REGURGITATION AND HAEMATEMESIS IN INFANTS
}

BY

\author{
W. G. WYLLIE, M.D., F.R.C.P. \\ Physician, Hospital for Sick Children, Great Ormond Street, \\ and \\ C. ELAINE FIELD, M.D., M.R.C.P. \\ First Assistant to the Children's Department, University College Hospital
}

Six infants of ages from one month to eighteen months have recently been examined by us because of apparently effortless intermittent vomiting which was often blood-stained. The symptoms they presented were fairly uniform. Vomiting or regurgitation, during or between feeds, dated from birth or soon afterwards; blood frequently appeared in the vomit-giving it a brown colour-or occurred in bright red patches or streaks. Between bouts the infant was cheerful and contented, but in periods of regurgitations was apathetic, sometimes looked strained, and might give a sharp cry before a vomit as if in pain. Gain in weight was slow and irregular, and some degree of anaemia was present. Occult blood could often be detected in the stools.

Review of the literature. We believe that these symptoms in infants have too often been attributed to bleeding peptic ulcers of the duodenum or stomach itself. Meiselas and Russakoff (1944), reviewing the literature, have drawn attention to the common finding of duodenal ulcer at autopsy in marasmic infants. Holt (1913) recorded 65 duodenal cases, of which the ages in 70 per cent. were between six months and fifteen months of age; the age incidence corresponding to the commonest period for marasmus. Of 64 infants with proved duodenal ulcers, 28 had blood in the stools, only 10 had bloody vomitus, and 6 had both. Bird, Limper, and Mayer (1941) give a ratio of two duodenal and pyloric to one gastric ulcer in the period from birth to fourteen days, and five to one between fifteen days and one year. They state that in the neonatal group the onset of symptoms is sudden and the ukers bleed severely or perforate, while in the later age-group abdominal pain, vomiting - sometimes streaked with blood-and melaena occur for weeks before the onset of graver symptoms. All these authorsexcept in the marasmic group, where an ulcer is found unexpectedly at autopsy-emphasize pylorospasm, projectile vomiting, and acute illness with serious complications (perforation) as common symptoms of duodenal and gastric ulcer in infants.

More tardily, and chiefly by radiographic help, it has been recognized that vomiting-or rather regurgitation of coffee-grounds or bright red blood -may occur either in the presence of oesophagitis, or of a peptic uker at the lower end of the oesophagus in cases of congenital short oesophagus with partial thoracic stomach. Oesophageal ukcer has been reported nearly always in adults, rarely in children. In 1929, Hurst and Stewart collected twelve cases of oesophageal peptic ulcer, and in the same year Chevalier Jackson remarked on thirty-one active ulcers and sixty-seven scars of healed ulcers in 4,000 endoscopies, all apparently in adults. Since 1933, Dick and Hurst (1942) saw sixteen fresh cases of peptic ulcer of the oesophagus in association with congenital shortness of the oesophagus; but the four males in their series were between twentytwo and seventy-two years of age at the onset of symptoms, and the twelve females between eighteen and twenty-six years. The delay in onset of symptoms with such a congenital condition as short oesophagus and partial thoracic stomach is difficult to account for. The abnormality, however, has been found at autopsy in a man of 77 years who had no symptoms during life. An entirely thoracic stomach can be present without symptoms (personal communication by Dr. W. E. Snell of a case discovered accidentally by $\mathrm{x}$ rays); yet its presence in an infant with inability to retain any of its feeds because of regurgitation brought about its death at twelve weeks (fig. 1). Apparently, therefore, symptoms due to congenitally short oesophagus with partial thoracic stomach can have their onset at any age, though, according to the records available up to date, more commonly in adult life than childhood.

In 1930, Kelly, and in 1931, Findlay and Kelly described nine cases of congenitally short cesophagus with partial thoracic stomach in children, seven boys and two girls, with ages from four weeks to nine years and ten months. In these cases there was apparent congenital stenosis of the oesophagus, in eight of which the food passage below the narrowing was proved by endoscopy to be part of the stomach. In 1933, Jacob, Tweedie and Negus described the case of an infant of one year and seven months who suffered from vomiting on and off since birth. An $x$ ray with barium suggested an oesophageal stricture opposite the sixth to eighth thoracic vertebrae, and endoscopy proved that the distal portion was part of the stomach. Haroen and Gerlings (1934), reported a case of a child who had vomited blood-stained material intermittently since she was a week old. Endoscopy revealed a short oesophagus with an ulcer at its lower end and a partial thoracic stomach. Dunhill's case (1935) was in an infant of eleven months, who had repeated vomiting tinged with blood during or twenty minutes 


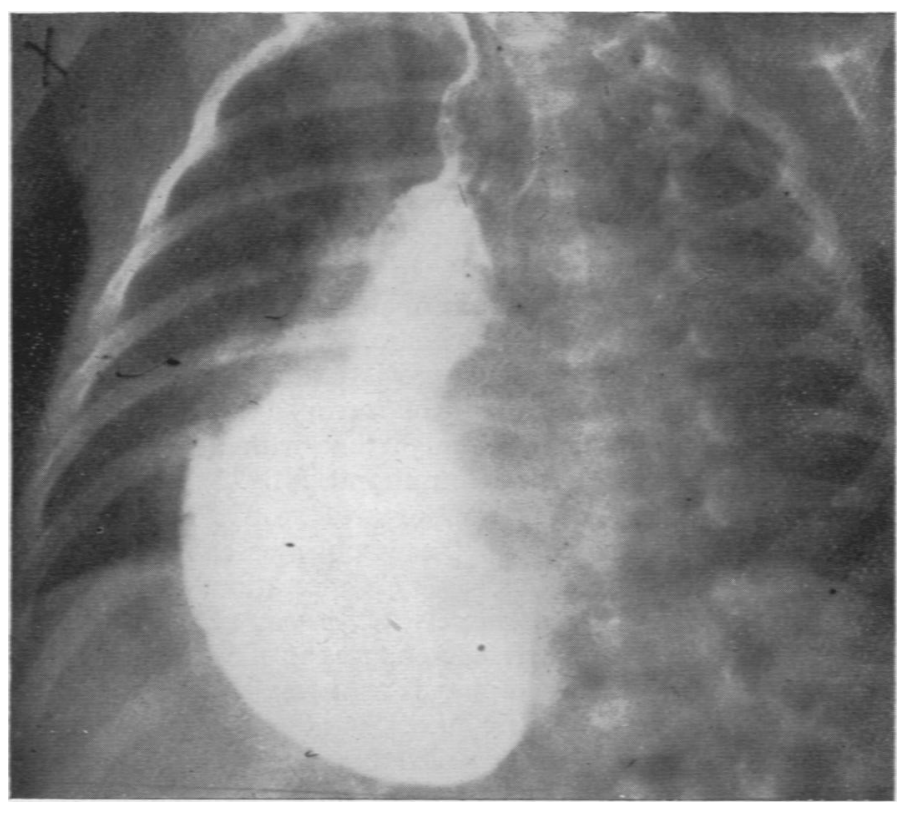

Fig. 1.-Thoracic stomach.

or so after a feed, with intervals of freedom up to fifteen days. With $\mathrm{x}$ rays and barium, gastric striae could be recognized in the supra-diaphragmatic portion of the stomach. On oesophagoscopy, an ulcer was seen in the lower end of the true oesophagus. Two other similar cases in early infancy were described, in 1940 by Lelong, Lamy, and Aimé, and in 1941 by Lesné, Rouget, and Longeaux. The interesting observation in these two reports was the absence of an associated constriction at the cardio-oesophageal juncture.

Most of the other reported cases, in infants as well as at later ages, have given on barium $x$-ray examination an appearance of one or two strictures. Oesophagoscopy shows the upper constriction to be just above the ulcer in the lower part of the oesophagus, a second contracture occurring below the ulcer at the oesophageo-gastric junction. The narrowings may in some cases be genuine stenosis, as it is not always possible to get the endoscope beyond the upper narrowing in order to see the ulcer; but the element of spasm immediately above the ulcer is important, and may simulate or exaggerate a stenosis. In radiographs of different dates the variations of degree of narrowing are often striking. Evidence of longitudinal striation seen above the level of the diaphragm in a barium $x$-ray is strongly in favour of an intrathoracic portion of the stomach.

In one of our six cases a stricture was present, but in the other five no narrowing was found. In one case the transition between oesophageal and gastric mucosa was seen by endoscopy (case 2) to be well above the diaphragm, thus indicating a short oesophagus. In three others no exact cardio-oesophageal demarcation was observed, but instead a gradual transition from a normal to a reddened swollen haemorrhagic mucosa. A possible explanation of the presence or absence of a constriction is that an ulcer is usually accompanied by spasm or stenosis on its proximal side. while an oesophagitis with haemorrhage can occur without spasm. It appears to have been this latter condition which was present in five of our cases.

Symptomatology. In adults the symptoms of peptic ulcer of the oesophagus, according to Hurst, are smarting or burning pain behind the sternum-sometimes heart-burn-felt while eating or drinking. The pain can be brought on by bending forward or lying down. In cases reported in infants and young children by Haroen and Gerlings, by Findlay and Kelly, and in our own cases, the symptoms noted were frequent spells of vomiting or regurgitation, often stained brown or red with blood, these occurring more often during a meal than later, and beginning from or soon after birth, or at the time of introduction to solid foods; the facial expression of the child, or a cry before regurgitation may suggest pain. The return of food seems to occur especially during recumbency-the commonest position of the infant-but even to some extent when being fed. The reason for this will be referred to later. Nutrition is usually poor, and anaemia present. In older children dysphagia is obvious; and Kelly, in cases with constriction of the oesophagus, mentions prolonged mastication and slow swallowing.

In the present series, screening of an infant during a barium swallow indicated the need for a more thorough investigation of all our cases and for making control observations on normal infants of the same age. In the latter the barium swallow normally descended in spindle-shaped boluses, which hesitated momentarily about the level of the diaphragm, entered the stomach, and did not return when the infant was placed in the supine position, even when pressure was exerted over the abdominal wall. On screening the affected infants in the supine position, however, the barium descended readily in most cases, but regurgitated with ease from stomach to oesophagus on inspiration. this probably being due to negative intrathoracic pressure which facilitated reopening of the oesophageal lumen. Manual pressure upon the abdomen during the procedure caused the re-entry of barium into the oesophagus to be greatly increased, even to the extent of its regurgitation into the mouth. There was evidently some incompetence at the cardia, or of the normal gastro-oesophageal valvular mechanism, which thus permitted a ready reflux of gastric contents.

Pathogenesis. Normally the oesophagus provides a one-way passage from mouth to stomach. Except 
in belching or vomiting, in which the diaphragm, stomach, and cardia obey a special pattern of nervous stimuli, air and food are not rejected from stomach to mouth. The normal mechanism of closure between oesophagus and stomach still is a subject of debate. Yet its adequacy is such that water can be drunk and retained with the head dependent or even with the subject standing on his head. Prevention of regurgitation is essential to avoid loss of ingested food and also to secure the mucosa of the lower end of the oesophagus against peptic digestion.

The theories of closure at the cardia, which possibly are not exclusive, are as follows. Chevalier Jackson attributed closure to a diaphragmatic pinchcock or hiatal narrowing, depending on special bundles of muscle of the diaphragmatic crura extending round the oesophagus at its lower end, and contributing to its closure, or co-ordinate opening during deglutition. In addition he stressed the fact that below the diaphragm the oesophagus takes a leftward inclination at an angle of fifty degrees. The diaphragmatic pillars exert a downward milking contraction during inspiration. He did not consider that a special cardiac sphincter existed in the oesophageal musculature. Negus states that evidence of a sphincter is absent in cases of short oesophagus with thoracic stomach. He rightly draws attention to the difference of pressure normally acting in the thoracic and abdominal portions of the oesophagus. There is reduced pressure within the thorax, especially during inspira-tion, thus permitting easier opening of the oesophagus; while in the abdomen the pressure is raised, facilitating closure of the abdominal oesophagus by apposition of the viscera, due to descent of the diaphragm and contraction of the crura with narrowing of the hiatus.

Hurst upheld the existence of an oesophageal sphincter somewhere in the cardiac antrum, i.e. between the hiatus and the junction with the stomach. Knight, by excision of the sympathetic fibres surrounding the coeliac axis and left gastric arteries in cats, caused the cardiac sphincter to become patulous, allowing regurgitation of gastric contents into the oesophagus. Lendrum, in 150 autopsy specimens at all ages from foetal to senility, could find no evidence of a circular band of muscle resembling a sphincter at the cardia. Yet in the study of cardiospasm he agreed with Hurst that disturbance of the myenteric vagal plexus (Auerbach) permitted the sympathetic fibres to the terminal portion of the oesophagus to act unopposed, causing want of the normal relaxation during the act of swallowing. It is also stated that achalasia at the cardia can occur when the cardia is situated within the thorax, producing a much greater degree of oesophageal dilatation than would occur with stenosis (Dunhill). Lendrum's anatomical studies demonstrated that at the cardiac orifice the left margin of the oesophagus continues into the greater curvature of the stomach, or its fundus, at an acute angle-the incisura cardiaca; the right margin of the oesophagus is continuous in a gentle curve with the lesser curvature of the stomach. The acute angle formed by the left margin of the oesophagus and the junction of the greater curvature forms a valve-like structure which readily allows substances to enter the stomach, but prevents regurgitation by apposition closure, by the result of direct pressure from the presence of air in the fundus of the stomach, and by the relatively greater intra-abdominal pressure. The mechanical valvelike method of closure is naturally inoperative or non-existent when the oesophagus is short and continuous in a straight line with the part of the stomach which is intrathoracic (fig. 2).

The regurgitation of acid gastric contents into the lower part of the oesophagus can give rise to (1) oesophagitis, and (2) ulceration. By ligation of the pylorus in rats, Selye was able to produce peptic haemorrhagic changes in the lower thoracic part of the oesophagus as a result of regurgitation of the acid gastric juice. In oesophagitis, numerous angry red rugae which bleed easily are visible at endoscopy, but an ulcer shows clear-cut margins and may vary greatly in size. Bartels' study of autopsy material at the Mayo Clinic suggests that oesophagitis can also occur in debilitated subjects in which the oesophagus is of normal length. He found ulcerative oesophagitis in 82 of 6,000 consecutive post-mortem examinations. The ages in the affected cases were between eight and seventy-eight years. In fifty-four cases the condition had followed upon an operation. A tendency to hyperacidity has been mentioned as a determining factor at all ages, in the occurrence of oesophagitis, or of ulceration in cases of short oesophagus, but it was not the controlling factor of the vomiting in our infantile cases, where a simple mechanical fault-a lax cardia or cardiac incompetence-appeared to be the chief cause. Another cause of bleeding or ulceration often mentioned is islands of ectopic gastric mucosa at the lower end of the oesophagus. There is no doubt that these frequently exist, but their importance seems much exaggerated.

It is incorrect to speak of hiatal hernia of part of

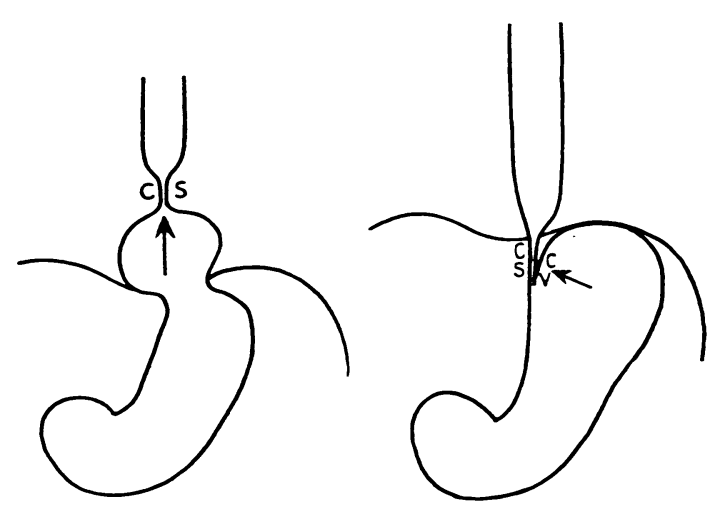

FIG. 2.-CS, Cardiac sphincter; CV, Cardiac valve.

From Dick and Hurst (1942). By kind permission of the Qwarterly Journal of Medicine. 
the stomach in cases of short oesophagus, as the want of development of the latter has prevented the normal complete descent of the stomach

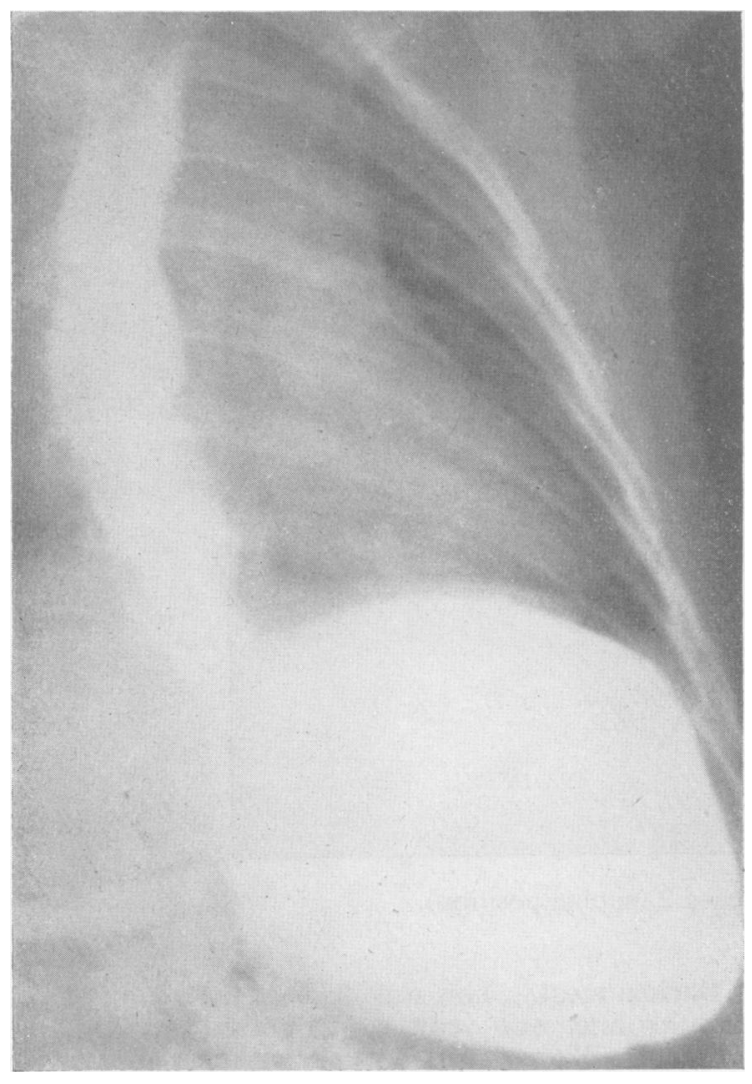

FIG. 3.-Barium swallow in case 1 (Trendelenburg position).

to below the diaphragm. The hiatus itself may be wider than normal, but is sufficiently competent to prevent any of the abdominal viscera being herniated into the thorax.

\section{Case Histories}

Case 1. A.B. was first seen at the age of one and a half years, when he weighed $19 \mathrm{lb}$. He had vomited periodically since birth, and on several occasions there had been visible blood in varying amounts, although 'brown mucus' had been vomited as early as nine weeks of age. At one year and two months a stool tested for occult blood was positive. He was born one month prematurely, his birth weight being $6 \mathrm{lb} .12 \mathrm{oz}$., and was breast fed for three months. Apart from an attack of pneumonia he had had no previous illnesses. The parents and five other children were all well.

Findings. There was no apparent wasting, but the child was $4 \mathrm{lb}$. underweight. Otherwise he was physically and mentally normal for his age. $\mathrm{He}$ vomited about once a day-brown-flecked material which had no particular relation to food. The benzidine test for blood was strongly positive for the vomit, but negative for the stool. The blood haemoglobin was 96 per cent.

Barium meal. The barium emptied satisfactorily into the stomach, but when the child was placed $\rightarrow$ in the supine position the barium flowed back easily into the oesophagus, which appeared to be dilated and to lack the usual smooth outline (fig. 3). There appeared to be no tone in the cardia 0 or oesophagus as, on deep inspiration, the latter dilated up to a diameter of $4 . \mathrm{cm}$. There was good emptying of the stomach in three hours, and no $\overrightarrow{\vec{D}}$ delay in the intestines.

Fractional test meal. This was normal, the total $\frac{0}{C}$ acids rising to $30 \mathrm{c} . \mathrm{cm}$. after three quarters of an $\overline{0}$ hour and falling to $10 \mathrm{c.cm}$. at the end of the hour. $\frac{\bar{c}}{\bar{\sigma}}$ The free acid never rose above $10 \mathrm{c.cm}$.

Oesophagoscopy. Performed by Professor R. S. Pilcher. Showed the upper part of the oesophagus $\infty$ to be fairly normal, with gradual transition to a $\overrightarrow{0}$ thick reddened mucosa with deep rugae. It was $\overrightarrow{\vec{H}}$ impossible to locate the exact position of the cardia $\vec{\omega}$ or commencement of the stomach, as no constriction $\frac{\sigma}{o}$ was seen. The oesophagus appeared to be dilated and atonic, and the mucus membrane bled easily although no actual ulcer crater was seen.

TREATMENT. Solid food, avoiding excess of $\vec{\circ}$ liquids, was tried, and the child was propped up $\infty$ after a meal for two or three hours. There was slight improvement in the vomiting but no gain in $\infty$ weight over a period of two months.

Case 2. C.D., aged one year and three months, weight $19 \mathrm{lb} .1 \frac{1}{2} \mathrm{Oz}$, had been vomiting intermittently $\varnothing_{\varnothing}$ since three days old; the vomit was often streaked 3 with blood. He was born three weeks prematurely after a long labour, birth weight $7 \frac{1}{4} \mathrm{lb}$. He was breast fed for six weeks.

FINDINGS. The infant was three pounds unde weight and looked poorly nourished. He appeared reluctant to swallow, and vomited once or twice a day, although there were periods of several days with no vomiting. Visible blood was often present $\bar{\partial}$ in the vomit, and the stool gave a positive benzidine reaction. Blood haemoglobin was 67 per cent. $\stackrel{\perp}{\varrho}$ Bleeding time (modification of Duke's method) $\overrightarrow{\vec{O}}$ 3 minutes 30 seconds, and clotting time (Dale and $\frac{9}{3}$ Laidlaw) 2 minutes 5 seconds.

Barium swallow and meal. At one year, two months. The report states that the barium was held up for a considerable time about the cardia, and that, when the test was repeated three weeks later, ? there was periodic hold-up at the cardia with con- $\frac{3}{3}$ siderable hold-up in the stomach after three hours. The $x$ ray (fig. 4 ) shows a patent cardia and dilated oesophagus with irregular outline. When repeated in another two weeks there was no hold up at the 을 cardia but a slight contraction one inch above it. $\rightarrow$ There was a pyloric hold-up for three hours. At two years and three months, the child was screened by Dr. L. G. Blair. There was no obstruc- or tion to the passage of barium into the stomach, but $N$ it flowed freely back into the oesophagus when the $N$ child was in the supine position. An $x$ ray taken $\omega$ at the time showed dilatation and irregularity along the whole length of the oesophagus, particularlyo the lower third. There was no constriction to denote $\Phi$ the position of the cardia.

Oesophagoscopy. (Mr. J. Crooks.) The transi- 7 tion from oesophageal to gastric mucosa occurred $\vec{P}$ at $20 \mathrm{~cm}$. from the incisor teeth without any recognizable sphincter or constriction. This is $3 \mathrm{~cm}$. $\frac{\vec{D}}{8}$ short of the normal distance for age from incisors $\frac{0}{\sigma}$ to cardia. An opaque bougie was passed to the 


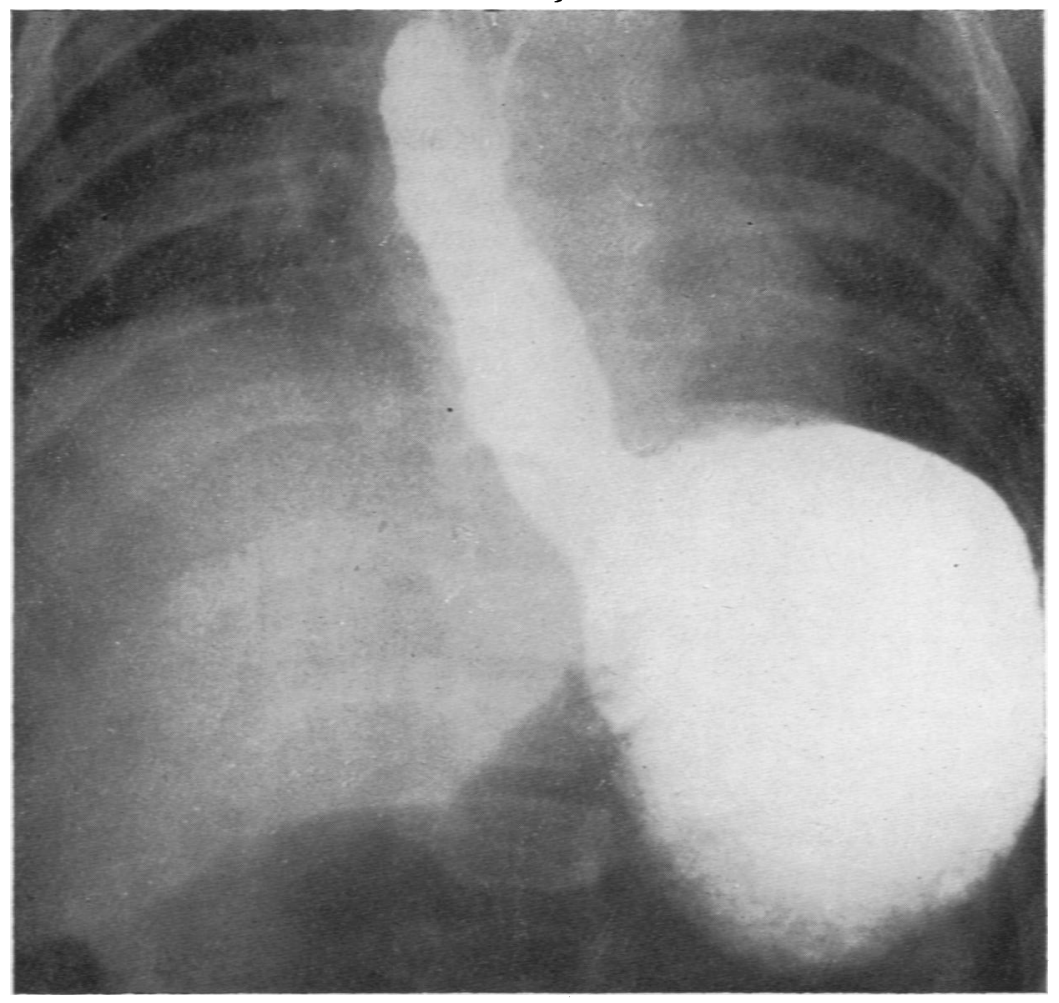

FIG. 4.-Barium swallow in case 2 (supine position).

site of mucosal transition, and an $\mathrm{x}$ ray proved this to be well above the diaphragm.

Treatment. Pylostropin (methylatropine nitrate), two lamellae before each feed, produced no alteration of the symptoms. Iron in the form of ferrous sulphate was given for the anaemia.

Progress. Whilst at a convalescent home he developed chickenpox and pneumonia. During this time vomiting became more frequent, producing dehydration. He was finally discharged home ten months after admission to hospital. He was vomiting less, having gained five pounds in the ten months; blood haemoglobin was 78 per cent.

Case 3. E. G., aged eleven months, weight $13 \mathrm{lb} .15 \mathrm{oz}$., had vomited since birth. Although he took feeds well, he vomited during or after most feeds, and even after solids. His birth weight was $7 \mathrm{lb} .14 \mathrm{oz}$., and he was breast fed for nine months. He was the first baby, and parents were healthy; pregnancy and labour were normal.

Findings. He was pale, hypotonic, and miserable, had two teeth, and could sit up. A few rhonchi were heard in the chest; otherwise there were no abnormal physical signs. Shortly after admission he developed bilateral otitis media which resolved after myringotomy. He vomited periodically whilst in hospital, sometimes as often as three or four times a day; then there might be no further vomiting for two or three days. The vomit frequently contained blood, and the stools showed a positive benzidine reaction. The blood haemoglobin was 69 per cent. and the leucocyte count 8,300 per c.mm.
Barium meal. This was done at the age of eleven months and one year, and showed no hold-up. Dr. L. G. Blair reports on a repeat meal at one year and ten months as follows: 'I could find no lesion in the stomach or duodenum. The child regurgitates food easily into the oesophagus, the lower end of which dilates rather easily.' When repeated again two weeks later, the oesophagus was observed to fill with barium from the stomach in the supine position, and on deep inspiration the oesophagus dilated up to $4 \mathrm{c.cm}$. in diameter.

Oesophagoscopy. Performed at one year, eleven months by Mr. J. Crooks. The oesophagoscope was passed for $23 \mathrm{~cm}$. There was no constriction or difficulty encountered at the cardia on passing the instrument. The mucus membrane of the oesophagus and stomach was very red and bled easily, and that of the oesophagus showed numerous angry rugae.

Progress. Intermittent vomiting, sometimes with blood, continued, but the child made satisfactory general progress and gained weight, being $22 \mathrm{lb}$. $10 \mathrm{oz}$. at one year, eleven months. The last blood count was quite normal. Haemoglobin 100 per cent. Leucocytes 11,200 per c.mm. of blood.

Case 4. H. J., weight 6 lb. 12 oz., first attended an infant welfare centre at the age of one month. The story was that he had vomited after practically every feed since birth. He was a full-term baby; delivery was normal, birth weight $7 \mathrm{lb} .6 \mathrm{oz}$. He was breast fed. Mother and father and one other child were healthy. 
Findings. There were no abnormal physical signs and the breast feeding was satisfactory.

Progress. He continued to vomit, and this was sometimes streaked with brown or contained bright red clots of blood. Sometimes he screamed as if in pain. In spite of the vomiting he continued to gain weight. At five months of age he was weaned and admitted to hospital, now weighing $14 \mathrm{lb} .11 \mathrm{oz}$.

Barium swallow. Observed at one month and repeated at five months of age, showed no hold-up, but on reviewing the $x$ rays three years later it was noticed that the pictures showed a dilated oeso-

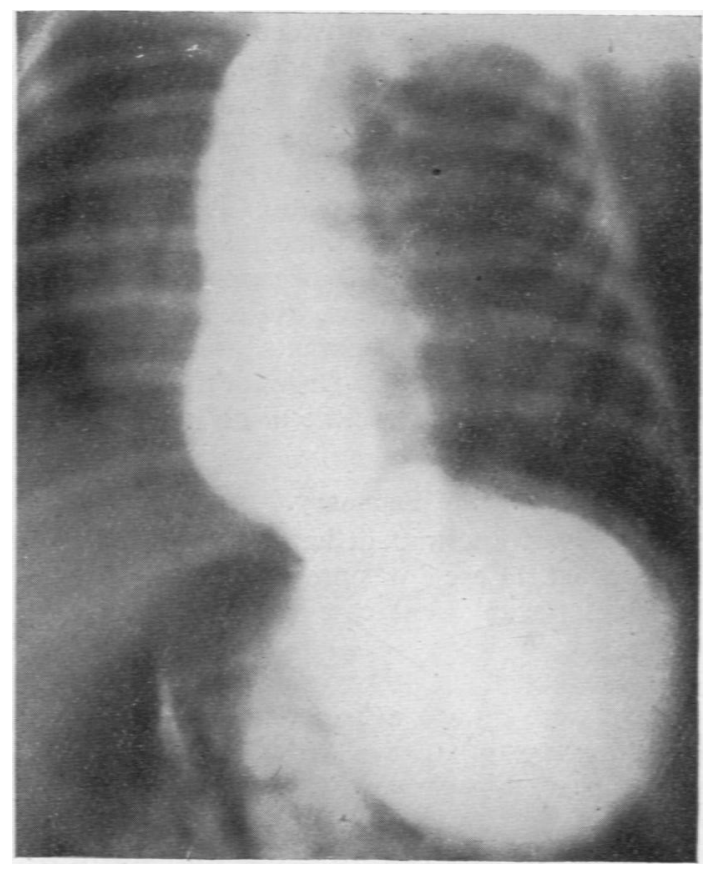

FIG. 5.-Barium swallow in case 4.

phagus filled with barium, and an open cardiac orifice (fig. 5). These findings were confirmed when a barium swallow was repeated at three years and nine months, and when he was lain down barium regurgitated with ease into the oesophagus, which appeared atonic and which dilated considerably on inspiration.

Barium meal. Taken at one month and repeated at five and at eleven months. Showed no difficulty in transit to stomach.

Fractional test meal. This was performed at five and at eleven months. There was no free $\mathbf{H C l}$. Total acids were $25 \mathrm{c} . \mathrm{cm}$. in the resting juice and fell to $10 \mathrm{c.cm}$. after a meal of gruel. Blood was present.

Stool. Benzidine test and spectroscopic examination strongly positive for blood.

Blood counts. These were repeated frequently, and only on one occasion was there a small reduction in the erythrocyte count.

Bleeding time. Three minutes fifteen seconds.

TREATMENT. Shortly after admission to hospital he developed loose stools, and, with the frequent vomiting, required intravenous therapy followed by $200 \mathrm{c} . \mathrm{cm}$. of blood. He was then tried on eumydrin, 1 c.cm. of 1 in 10,000 solution before each feed, and vomiting ceased, returning when the drug was discontinued. Pylostropin, one lamella before each feed, was then tried, and again vomiting ceased. The pylostropin was finally discontinued after six weeks of treatment, the child having then about one small vomit a day.

Further Progress. The infant was finally discharged home from hospital at nine months of age, but returned in one week, vomiting again with streaks of blood, and once a teacupful of blood. Haemoglobin had dropped to $68 \mathrm{per}$ cent. He was again treated with pylostropin and sent home. Vomiting slowly improved, but he began to have convulsions, with loss of consciousness, which have now been diagnosed as epilepsy. Vomiting finally ceased at a year old.

At three years, nine months the case was reviewed. There had been no further vomiting, but the epileptic fits continued. A barium swallow at this time has already been described.

Oesophagoscopy. At three years and nine months. Professor R. S. Pilcher reported: - The upper part of the oesophagus was normal. At $25 \mathrm{~cm}$. the respiratory movements were almost absent and the mucosa was folded longitudinally, the folds being in contact. The oesophagoscope passed through these folds for $3 \mathrm{~cm}$., where the view was obscured by fluid-presumably gastric contents. The mucosa between $25 \mathrm{~cm}$. and $28 \mathrm{~cm}$. may be gastric, and I think the cardia was at about $28 \mathrm{~cm}$. distance.'

Case 5. K. L. was admitted to hospital at the age of one year and two months, weight $12 \mathrm{lb} .12 \mathrm{oz}$. She was said to have been vomiting two or three times a day since five months old, usually immediately after food. Sometimes the vomits were flecked with blood or like thick chocolate. On one occasion stools were black. She was a premature baby, birth weight $4 \mathrm{lb}$. Delivery was normal, and she was breast fed for five months, but vomiting started before weaning. There were four other children, all premature; one died at eight days. Parents were healthy.

Findings. She looked well and was a happy child and only once appeared to have pain.

Barium swallow. Showed no abnormality. The barium passed into the stomach without obstruction, but regurgitation was not particularly looked for.

Barium meal. On two occasions showed no abnormality and nothing to suggest gastric or duodenal ulceration.

Fractional test meal. Performed twice. On both occasions the free and total acid contents rose during the three hours The free $\mathrm{HCl}$ in the resting juice was $5 \mathrm{c.cm}$. on both occasions, rising to $35 \mathrm{c.cm}$. and $50 \mathrm{c.cm}$. respectively in three hours. The total acids were $10 \mathrm{c.cm}$. in the resting juice, rising to $50 \mathrm{c.cm}$. and $70 \mathrm{c.cm}$. in three hours. Blood was present in all specimens, but no bile.

Blood count. Erythrocytes $4,150,000$ per c.mm. of blood. Haemoglobin 72 per cent. Colour index $0 \cdot 86$. Leucocytes 11,800 per c.mm. of blood, platelets 230,000 per c.mm.

Bleeding time. One minute thirty seconds (reported normal one to three minutes). Coagulation time four minutes (normal two to six minutes).

Oesophagoscopy. Not performed.

TREATMENT. A variety of treatments were tried, including a milk diet and alkalies as for an ulcer, also belladonna and olive oil, but the child continued 
to vomit with periodic large haematemeses, and on one occasion this appeared to be preceded by pain.

Progress. She was finally discharged home in a good phase, and owing to distance has not been seen since. But the mother writes stating that she continued to vomit until three and a half years of age. Periodically she would vomit chocolatecoloured material, and at these times her motions were black. The mother's last letter states that she is now five years and three months, weighs $2 \mathrm{st} .6 \mathrm{lb}$., and has had no further vomiting for the last year and a half.

Case 6. M. P. was admitted to hospital at one year old with the story that she had had dark vomits since birth, diminishing in frequency as she grew older. At feed times she became restless as if in pain, and this appeared to be relieved by vomiting. There was one other child in the family, and parents were healthy.

FINDINGs. She was a cheerful child with pale sallow complexion. She was thin, weighing only $15 \mathrm{lb}$. $9 \frac{1}{2} \mathrm{oz}$. She vomited repeatedly several times during a meal, and the vomit frequently contained blood.

Blood count. Erythrocytes 4,300,000 per c.mm. of blood. Haemoglobin 68 per cent. Colour index 0.79. Leucocytes 20,000 per c.mm. Platelets 180,000 per c.mm.

Bleeding time. Three minutes. Coagulation time, one minute thirty seconds.

Stool. Benzidine test and spectroscopic examination positive for blood.

Fractional test meal. At three years, two months, showed no free $\mathrm{HCl}$ in the resting juice, and only $10 \mathrm{c.cm}$. of total acids. Two and a half hours after the gruel the free $\mathrm{HCl}$ rose to $25 \mathrm{c.cm}$. and the total acid to $45 \mathrm{c} . \mathrm{cm}$. Flecks of blood were present, but no bile.

Barium meal. At one year showed marked peristalsis of the stomach, but no hold-up at the pylorus; no ulcer crater was seen. It was repeated at three years, two months, and no abnormality was detected.

TREATMENT. No particular treatment was given, except iron for the anaemia.

Progress. She was finally discharged home, but continued to have blood vomits and later complained of pain in her abdomen. She was readmitted to hospital twice for these symptoms. She looked well, had no anaemia (haemoglobin 101 per cent.), but still continued to vomit occasionally. No blood was this time detected in the vomit.

Barium swallow. At three years, nine months. On first impression there appeared to be no hold-up to the barium, but closer observation revealedat about $3 \mathrm{~cm}$. from the cardia and $2 \frac{1}{4} \mathrm{~cm}$. from the diaphragm - a momentary hesitation to the passage of the barium, which then passed on into the stomach as a thin ribbon-like column. This finding was constant with each swallow. There was no definite dilatation of the oesophagus above, and no regurgitation of barium from the stomach.

Oesophagoscopy. Performed by Mr. J. Crooks. - The oesophagoscope passed for $20 \mathrm{~cm}$. from the teeth. The lower $4 \mathrm{~cm}$. of oesophagus was stenosed to about the thickness of a pocket-book pencil and ulcerated, bleeding easily. The cardia was not seen.'

\section{Treatment}

An important factor in facilitating the vomiting in cases of incompetence of the cardia and short oesophagus is decubitus, notably in the supine position. As this is the normal posture for infants, it explains the ease with which acid gastric contents regurgitate. This was certainly so in the cases observed by us; but in the more numerous cases of short oesophagus reported with onset of symptoms in adult life, no history is provided of difficulties encountered during infantile feeding. We found the most satisfactory treatment was to raise the head of the cot on blocks, to prop the infant up on pillows to prevent regurgitations, and to give thickened feeds. A more upright position is automatically assumed as the age of weaning takes place, which may explain why in all our cases gradually the regurgitations became less. Without any other particular treatment these infants usually recover by two or three years of age. Drugs of the belladonnaatropine group produced little or no improvement.

\section{Summary}

Six cases of intermittent haematemesis in infants are reported. Case 2 was proved to be a congenital short oesophagus, and case 6 a stricture of the oesophagus.

It is suggested that the symptoms in cases 1, 3, 4 and 5 were due to a lax or incompetent cardia permitting regurgitation of gastric contents, thereby causing haemorrhagic oesophagitis.

Our thanks are due to Professor R. S. Pilcher and Mr. J. Crooks for the endoscopic examinations.

\section{REFERENCES}

Bartels, E. C. (1935). Arch. Pathol., 20, 369.

Bird, C. E., Limper, M. A., and Mayer, J. M. (1941). Ann. Surg., 114, 526.

Dick, R. C. S., and Hurst, A. (1942). Quart. J. Med., 11, 105.

Dunhill, T. (1935). Brit. J. Surg., 22, 475.

Findlay, L., and Kelly, A. B. (1931). J. Larıng., 46, 797.

Haroen, I. L., and Gerlings, P. G. (1934). Acta Otolaryng., Stockh., 19, 461.

Holt, L. E. (1913). Amer. J. Dis. Child., 6, 381.

Hurst, A. F., and Stewart, M. J. (1929). Gastric and Duodenal Ulcer. London.

Jackson, Chevalier (1922). Laryngoscope, 32, 139.

Jacob, F. H., Tweedie, A., and Negus, V. E. (1933). J. Laryng., 48, 486 .

Kelly, A. B. (1930). Ibid., 45, 680.

Knight, G. C. (1934). Brit. J. Surg., 22, 155.

Lelong, M., Lamy, M., and Aimé, P. (1940). Bull. Mem. Soc. méd. Hôp., Paris, 56, 681.

Lendrum, F. C. (1937). Arch. intern. Med., 59, 474.

Lesné, M. E., Rouget, D., and Longeaux, S. (1941). Bull. Mem. Soc. méd. Hôp., Paris, 56, 687.

Meiselas, L. E., and Russakoff, A. H. (1944). Amer. J. Dis. Child., 67, 384.

Negus, V. E. (1942). Proc. roy. Soc. Med., Sect. Larying., 36, 85.

Selye, H. (1938). Canad. med. Ass. J., 39, 447. 